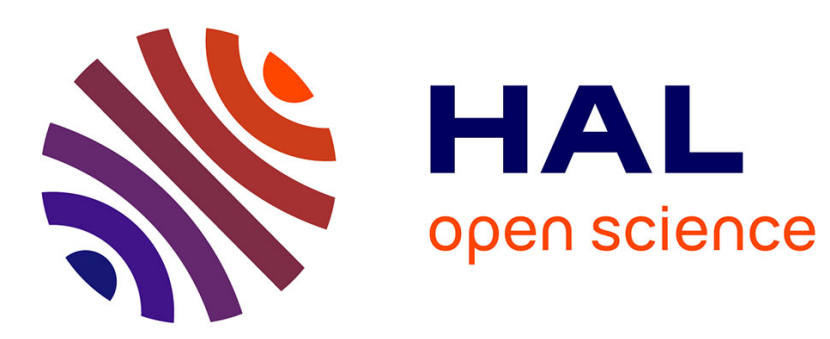

\title{
Using PESTELMO to Frame HCI Contextual Development in Developing Countries
}

\author{
Catherine G. Mkude, Maria A. Wimmer
}

\section{To cite this version:}

Catherine G. Mkude, Maria A. Wimmer. Using PESTELMO to Frame HCI Contextual Development in Developing Countries. 15th International Conference on Social Implications of Computers in Developing Countries (ICT4D), May 2019, Dar es Salaam, Tanzania. pp.326-333, 10.1007/978-3-03019115-3_27. hal-02281293

\section{HAL Id: hal-02281293 \\ https://hal.inria.fr/hal-02281293}

Submitted on 9 Sep 2019

HAL is a multi-disciplinary open access archive for the deposit and dissemination of scientific research documents, whether they are published or not. The documents may come from teaching and research institutions in France or abroad, or from public or private research centers.
L'archive ouverte pluridisciplinaire HAL, est destinée au dépôt et à la diffusion de documents scientifiques de niveau recherche, publiés ou non, émanant des établissements d'enseignement et de recherche français ou étrangers, des laboratoires publics ou privés. 


\title{
Using PESTELMO to Frame HCI Contextual Development in Developing Countries
}

\begin{abstract}
HCI4D is context-oriented. Literature highlights that successful implementation of HCI solutions in developing countries needs deeper understanding of the context. Despite numerous literatures pointing the importance of context-oriented HCI4D, there is no holistic method that guides researchers and implementers of HCI solutions in analysing different contexts of countries. To bridge this gap, this paper introduces the PESTELMO (Political, Economic, Socio-cultural, Technological, Environmental, Managerial and Organisational) analysis method for holistic analysis of contexts in which HCI4D is researched or implemented. PESTELMO analysis method is proposed in this research as an integrated approach to analyse the external and internal environment surround HCI4D research or deployment, as a suitable method for analysis of dynamic political, economic, socio-cultural, technological, environmental and legal parameters in long-term planning and finally as a holistic approach to assess relations, interactions and interdependences among the PESTELMO factors and sub-factors.
\end{abstract}

Keywords: HCI4D, ICT4D, PESTELMO, Developing Countries, Developed Countries

\section{Introduction}

Sustainable development is among the key issues in the current global conversations on socio-economic development agendas. The role of Computer Science and related disciplines/fields, including HCI, is clearly reflected in global development agendas. For instance, the UN has highlighted the importance of technology to achieve each of the Sustainable Development Goals [16]. In developing countries, information and communication technologies are heavily embedded in all aspects of socio-economic development in the formal and informal employment sectors. In the latter, ICT enabled financial services using mobile phones and other PDAs, especially mobile money, have become the core of business opportunities.

The diffusion of information and communication technologies and tools in developing countries, and to rural and marginalised communities continues to be very high. Consequently, diverse needs, preferences and abilities in using information and communication technologies, tools and gadgets emerge. These users' needs, 
preferences and abilities must be catered for in order to achieve the potentials of technologies and tools in socio-economic developments. In an attempt to cater for the Tanzanian majority diverse needs, for the first time in 2017, Tigo (Tanzanian Telecommunication Company) "[launched] a smartphone with a Swahili menu [...] which opened up digital access and adoption in Tanzania to majority of the population who use Swahili as the primary language of instruction" [15]. Such efforts clearly highlight the need to contextualise HCI developments taking into consideration the surroundings in which $\mathrm{HCI}$ is operationalised.

Research in HCI is abundant on one hand and falls in different application domains including education, health, finance, communication and politics. On the other hand, research in HCI4D has proven to be among the fast growing field in which key interests have been the contextualisation of HCI to fit the application area and needs [6]. There are numerous factors in HCI4D that are yet to be understood such as social, technological and cultural factors, especially in developing regions. This paper serves to contribute in HCI4D research by proposing PESTELMO analysis method for contextualising HCI4D towards effective and meaningful implementations in developing regions. The paper proposes the PESTELMO analysis method to address the knowledge gap in contextualising HCI4D based on literature review and previous work of the authors in ICT4D-based research.

The remainder of the paper is as follows: section 2 sets the grounds of the research and provides insights into the need for a holistic analysis method for contextualising HCI4D. Section 3 presents the PESTELMO analysis method. The value-add of the method in HCI4D is then reflected in section 4. Finally, section 5 concludes the paper and provides directions for future research.

\section{Setting the grounds and related work}

Ho and colleagues define HCI4D as "a subfield of ICT4D that focuses on understanding how people and computers interact in developing regions and on designing systems and products specifically for these contexts." [7]. The understanding of different technological and systems needs of developing countries that is different from those in developed countries has long been pointed out in literature. The notion that information and communication technologies, tools and systems made in developed countries cannot simply be directly applied to developing countries has also been discussed by different scholars (see [4][5][8][11][13]). These authors have called for better understanding of the users, context, infrastructure, resource settings and other factors when deploying a new technologies and information systems. We collectively term these factors as contextual factors that define the context of a certain region/country. A context of a region/country is 
generally defined as the environment in which a region/country functions and is defined by aspects that differ from one region/country to the other such as policies, people and culture, political and democratic practices, economic status, information systems, availability of ICT infrastructure, ICT literacy of public sector staff and citizens etc. [11].

Contextual understanding continues to be at the centre of HCI4D because of the heavy reliance of developing countries on developed countries on new and sophisticated technologies and information systems. Developing countries rely on developed countries for their expertise, experiences, design approaches and solutions; hence, facilitating a transfer of the same among the countries. Chetty and Grinter point out that the developed world, where HCI technologies, methods and systems are borne, has much to offer to the developing world [5]. However, the authors caution that it is essential for the differences between the two contexts to be recognised for building useful and useable systems in the developing world (ibid.).

A "context-oriented" approach involves assessment of whether e-government systems design and implementation approaches from one country are applicable and valuable in another's context ([9][14]). Similarly, Dell and Kumar's extensive work highlights a context-focused approach in designing, developing and implementing HCI technologies and tools [6]. The authors argue that even though research communities in HCI4D understand that each context is unique, there is a need of clarity in parts that are context-dependent and others that are not (ibid). In similar lines, Burrell and Toyama call for empiricism in research related in ICT for socioeconomic development, i.e. non-dogmatic approach to flexibly design and implement ICT tools, technologies and information systems that best suite certain context [3]. The authors depict practical example that is still relevant today in HCI4D - "the preferences of mobile phone users in downtown New York will likely not have much in common with the mobile phone preferences of fishermen in Uganda" (ibid). In the same perspective, as mentioned earlier, starting 2017 a Tanzanian telecommunication company Tigo is offering Tecno smartphones with a Swahili menu to enhance the uptake of smartphones by wider communities.

In another empirical study, Gitau and colleagues emphasise that HCI developers must take into account the social settings and different constraints of users of HCI technologies and tools in particular context [7]. An account of context-oriented mindset in developing HCI technologies and tools effectively contributes to socioeconomic development issues intended for.

The previous paragraphs have established the need to contextualise HCI4D. The basic question that remains is the general understanding of what constitutes "context". Table 1 presents a literature scan of factors that need to be analysed in different contexts before deploying HCI technologies, tools and systems. 
Table 1. Contextual factors of analysis before deployment of HCI technologies, tools and systems.

\begin{tabular}{ll}
\hline Literature source & What constitute context \\
\hline Brewer et al [2] & Language, literacy \\
Burrell and Toyama [3] & $\begin{array}{l}\text { Political practices, economy, culture, ecology, } \\
\text { policy, people, technology, infrastructure }\end{array}$ \\
Chetty and Grinter [5] & Technology, people, infrastructure, literacy \\
Dell and Kumar [6] & $\begin{array}{l}\text { Social factors, culture, infrastructure, language, } \\
\text { people, literacy, finances, }\end{array}$ \\
Gitau et al [7] & People, literacy \\
Ho et al [9] & $\begin{array}{l}\text { Infrastructure, people, culture, literacy, } \\
\text { environment, technology, financial aspects, social } \\
\text { aspects }\end{array}$ \\
Policies, people and culture, political and \\
democratic practices, economic status, information \\
systems, availability of ICT infrastructure, ICT \\
literacy of public sector staff and citizens
\end{tabular}

Table 1 depicts similarities and differences of factors of consideration when describing a context before deployment of HCI. Some authors mention two factors while others mention as many as eight factors. The differences in these factors affect how researchers formulate HCI4D and implementers deploy HCI4D solutions. Therefore, it is imperative that a holistic analysis method is in place to guide researchers and implementers to better understand the contexts in which they are involved in. The following section introduces the PESTELMO analysis method and describes its characteristics.

\section{PESTELMO analysis method}

PESTELMO ( Political, Economic, Socio-cultural, Technological, Environmental,

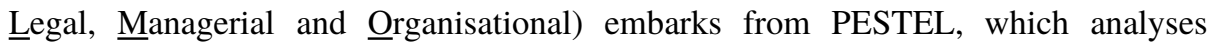
macro-environmental factors in strategic planning [18]. Dinçer (2004), cited by Yüksel, argues that the PESTEL analysis is a "pre-condition analysis which should be utilised in strategic management" (ibid.). Since first introduced by Aguilar in 1967 as ETPS (economic, technical, political and social), several modifications have been applied [1]. Richardson used PEST/STEPE with an additional ' $E$ ' in his study to scan the environmental changes and identify the barriers and constraints in developing 
libraries [12]. Katko introduced the legal factor ' $L$ ' and the environmental factor ' $E$ ' to the ETPS of Aguilar (1967) but changed the other ' $E$ ' to ecological to assess the development of traffic safety [10]. Similar to Katko, Yüksel added the legal and environmental factors to ETPS, and modified the 'S' to include socio-cultural factors to form PESTEL [18].

In this paper, we use PESTELMO analysis method first introduced in [10] to ensure that the multidisciplinary nature surrounding the fields HCI4D, ICT4D and egovernment are taken into account [17]. Furthermore, the method is recommended for three purposes outlined below:

1. An integrated approach to analyse the external and internal environment surround HCI4D research or deployment

2. A suitable method for analysis of dynamic political, economic, socio-cultural, technological, environmental and legal parameters in long-term planning

3. A holistic approach to assess relations, interactions and interdependences among the PESTELMO factors and sub-factors

Fig. 1 presents the PESTELMO analysis method for contextualising HCI4D. The first level of the model contains a title of the model (the HCI4D researchers and implementers specify in $(\mathrm{N})$ the name of a country or an organisation). The second level of the model contains the main categories of PESTELMO. The third level contains the factors identified by researchers/implementers (such as those mentioned in Table 1).

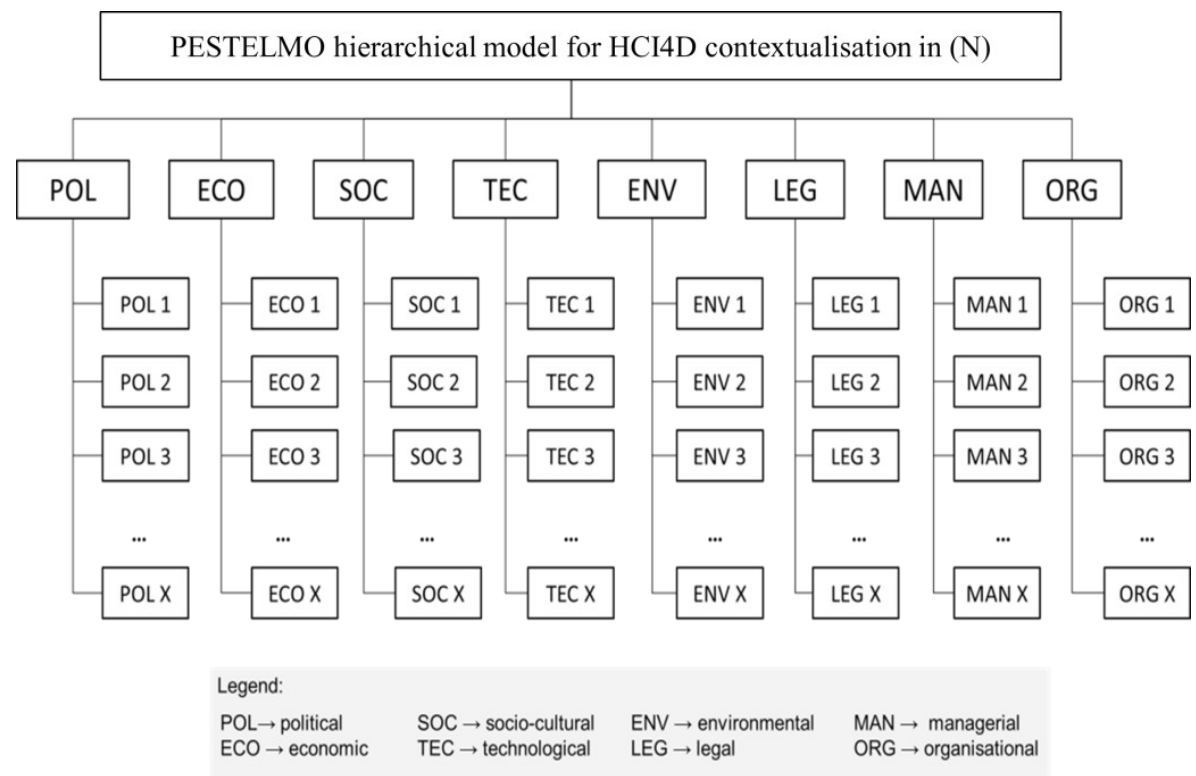

Fig. 1. PESTELMO hierarchical model for HCI4D contextualization in country/organization 
In the following section, the value add of PESTELMO analysis method is discussed and an exemplification is provided.

\section{PESTELMO for HCI4D}

In section 2, it was established that an account of context-oriented mind-set in developing HCI technologies, tools and solutions effectively contributes to socioeconomic development issues intended for. PESTELMO is introduced to provide a holistic analysis of the contexts in which HCI4D research is conducted or solutions implemented.

First, a context is analysed along the main factors of PESTELMO: political, economic, socio-cultural, technological, environmental, legal, managerial and organisational. Second, within each main factor, an analysis of sub-factors is made. For instance, in reference to the factors outlined in Table 1, the following is the analysis under the PESTELMO method:

Political: the analysis in this factor looks into the policies at the national level that support research, development and implementation of HCI at all levels of the government and in both the public and private sectors. Also, the democratic and political practices are looked into to analyse whether a government advocates HCI research and implementation in development sectors.

Economic: the analysis in this factor looks into the economy of a country to fund HCI research and implementation, and support maintenance. This factor also analyses the financial capabilities of users to buy HCI solutions. For instance, a solution in country A might not be effective in country B because users cannot afford it.

Socio-cultural: in this factor, numerous aspects are analysed such as: the cultural influence to research and use certain HCI solution, gender influencers, literacy level of users, literacy level of ICT staff in public and private sectors, language used in HCI solutions and localization of content.

Technological: the main sub-factor is analysis of availability of infrastructure to support deployment of HCI solutions. For example, a successful implementation of a rural mobile health information system depends on, among other things, availability of reliable network connectivity.

Environmental: this factor looks into the environment-related factors that can facilitate or hinder the successful implementation of HCI solutions. For instance, a lack of proper e-waste mechanism in an area might hinder further $\mathrm{HCI}$ solutions that produce more e-waste.

Legal: in this factor, legal aspects existing in a country in relation to HCI research and implementation are analysed. For instance, it includes an analysis of laws or regulations that regulate the implementation of HCI solutions for disabled. In another 
instance, it includes presence of laws that regulates age appropriate HCI solutions, etc.

Managerial: this factor analyses managerial aspects that support implementation of HCI solutions in the public and private sectors. Furthermore, it looks into the managerial commitment to promote HCI solutions.

Organisational: this factor analyses the organisational settings that support HCI implementation. For example, it analyses the acceptance of HCI in organisations. This factor also analyses aspects such as organisational inertia towards acceptance of new HCI solutions in the public and private sectors.

Following analysis of PESTELMO main and sub-factors, the context is analysed further by looking into the interdependencies among the sub-factors. A deeper understanding of a context is required to ensure that HCI solutions are robust and sustained. Furthermore, For example, there is a need to understand if there are interdependencies between the literacy level and culture of people. In another example, poverty might have interdependencies with literacy level of people. Further studies into the interdependencies of HCI4D contextual factors are included in future research.

\section{Conclusion}

An effective implementation of HCI4D depends on whether the context of a country in which the solutions are deployed has been taken into account. Literature mentions numerous factors that define a context a country and that are important to be understood in HCI4D. However, there is no holistic analysis method to guide HCI4D researchers and implementers in understanding the context of a country in which they research or implement HCI4D solutions. In this regard, the main contribution of this paper is to propose a holistic method for analysing a context in which HCI solutions are researched or implemented. This paper proposes the PESTELMO analysis method for contextualisation of HCI4D in any country or organisation.

The PESTELMO analysis method is proposed in this paper for three main reasons: as an integrated approach to analyse the external and internal environment surround HCI4D research or deployment, a suitable method for analysis of dynamic political, economic, socio-cultural, technological, environmental and legal parameters in longterm planning and finally a holistic approach to assess relations, interactions and interdependences among the PESTELMO factors and sub-factors.

Future research includes application of PESTELMO analysis method in the research field or implementation of HCI solutions and analysis of interdependencies among the contextual factors. 


\section{References}

[1] Aguilar, F. J.: Scanning the Business Environment. Macmillan, New York (1967).

[2] Brewer, E., Demmer, M., Du, B., Ho, M., Kam, M., Nedevschi, S., Pal, J., Patra, R., Surana, S., Fall, K.: The case for technology in developing regions. Computer 38(6), pp. 25-38 (2005).

[3] Burrell, J., Toyama, K.: What Constitutes Good ICTD Research? Information Technologies and International Development 5(3), pp. 82-94 (2009).

[4] Chen, Y. N., Chen, H. M., Huang, W. Ching, R.K.H.: E-government strategies in developed and developing countries: An implementation framework and case study. Journal of Global Information Management (JGIM) 14 (1), pp. 23-46 (2006).

[5] Chetty, M., Grinter, R.: HCI4D: HCI Challenges in the Global South. In CHI '07 Extended Abstracts on Human Factors in Computing Systems (CHI EA '07), pp. 23272332. ACM, California, USA (2007)

[6] Dell, N., Kumar, N.: The ins and outs of HCI for development. In Proceedings of the 2016 CHI conference on human factors in computing systems, pp. 2220-2232. ACM, Seoul, South Korea (2016).

[7] Gitau, S., Marsden, G., Donner, J.: After Access: Challenges Facing Mobile-only Internet Users in the Developing World. In Human Factors in Computing Systems (CHI '10) pp. 2603-2606 (2010).

[8] Heeks, R.: Information Systems and Developing Countries: Failure, Success and Local Improvisations. The Information Society 18 (2), pp. 101-112 (2002).

[9] Ho, M., Smyth, T., Kam, M., Dearden, A.: Human-Computer Interaction for Development: The Past, Present, and Future. Information Technologies and International Development 5(4), 1-18 (2009).

[10] Katko, T. S.: Road Safety Fatalities, Management, and Policy in Finland, 1970-2003. Public Works Management and Policy 11(2), pp. 126-138 (2006).

[11] Mkude, C. G.: Framework for E-Government Systems Design and Implementation for Developing Countries. Fölbach Verlag, Koblenz, Germany (2016).

[12] Richardson, J. V.: The library and information economy in Turkmenistan. IFLA Journal 32 (2), pp. 131-139 (2006).

[13] Sæbø, O.: E-government in Tanzania: Current Status and Future Challenges. In: Scholl, H. J., Janssen, M., Wimmer, M. A., Moe, C. E., Flak, L. S. (eds.) Electronic Government (EGOV 2012), LNCS 7443, pp. 198-209. Springer, Heidelberg (2012).

[14] Schuppan, T.: E-Government in developing countries: Experiences from sub-Saharan Africa. In: Government Information Quarterly, 26 (1), pp. 118-127 (2009)

[15] TIGO, https://www.tigo.co.tz/news/tigo-launches-4g-network-in-tanzania, last accessed 2018/201/10.

[16] UN Sustainable Development Goals, https://sustainabledevelopment.un.org/sdgs, last accessed 2018/10/10.

[17] Wimmer, M. A.: The role of research in successful e-government implementation. In: Zechner, A. (ed) E-Government Guide Germany. Strategies, Solutions and Efficiency. Fraunhofer IRB, Stuttgart pp. 79-87 (2007). 
[18] Yüksel, I.: Developing a Multi-Criteria Decision Making Model for PESTEL Analysis. In: International Journal of Business \& Management, 7 (24), pp. 52-66 (2012) 